\title{
PERCEPCIJA STUDENATA O ZNAČAJU OBUKE IZ HOTELSKIH INFORMACIONIH SISTEMA TOKOM STUDIJA
}

\author{
Milan Ivkov', \\ Ivana Blešić1, \\ Sanja Božić
}

'Departman za geografiju, turizam i hotelijerstvo, Prirodno-matematički fakultet, Novi Sad, Srbija

Correspondence:

Milan Ivkov

e-mail:

milan.ivkov@dgt.uns.ac.rs

\begin{abstract}
Rezime:
Jedan od osnovnih ciljeva visokog obrazovanja iz oblasti hotelijerstva jeste osposobljavanje studenata za budući rad u privrednom sektoru. U tom smislu, globalno se insistira na praktičnom radu tokom studija u relevantnim ugostiteljskim objektima. Dodatni način osposobljavanja studenata za budući rad jeste prilagođavanje kabinetske nastave zahtevima tržišta, prvenstveno $\mathrm{u}$ oblasti informacionih tehnologija i marketinga. Osnova rada jeste istraživanje sprovedeno među studentima hotelijerstva i turizma ( $n=100)$, koji u okviru predmeta Hotelska prodaja i recepcijsko poslovanje, na Prirodno-matematičkom fakultetu u Novom Sadu, prolaze obuku za rad u softveru za upravljanje hotelom Micros-Fidelio Suite 8. Cilj rada jeste prikazivanje percepcije studenata o značaju ovakve obuke za sticanje praktičnih veština i kompetencija za rad u hotelijerstvu, kao i za unapređenje kvaliteta studija. Rezultati rada ukazuju na visok stepen svesti studenata o značaju sticanja praktičnih znanja tokom studija u cilju ličnog usavršavanja i konkurentnosti prilikom zapošljavanja. Takođe, prikazana je uspešnost obuke u zavisnosti od pola ispitanika i njihovog usmerenja na studijama.
\end{abstract}

Ključne reči:

obrazovanje, kvalitet studija, percepcija studenata, hotelijerstvo,

Micros-Fidelio Suite 8.

\section{Obrazovanje}

Obrazovanje je najčešće osnov uspeha u životu, ono priprema i osposobljava ljude za rad. Ako se kroz visoko obrazovanje ne mogu osposobiti ljudi za rad, onda bi se moglo postaviti pitanje zašto da se ono finansira ili zašto da se studenti uopšte opredele za studiranje. Formalno obrazovanje uglavnom nije dovoljno da mladim ljudima pruži sva neophodna znanja pre nego što se zaposle i započnu svoju radnu karijeru.

Obrazovni sistem mora stalno da se menja jer se znanja stalno obnavljaju i inoviraju [1]. Svakako, visoko obrazovanje mora pratiti potrebe tržišta i poslodavaca [2]. Poslodavci očekuju radne sposobnosti i praktično znanje od potencijalnih radnika, dok s druge strane, studenti očekuju da steknu potrebna znanje i veštine tokom studija koje će im olakšati pronalaženje posla. Stoga, visoko obrazovanje koje implementira praktičan rad upravo stavlja akcenat na unapređenje kvaliteta studija, odnosno osposobljenosti 
studenata za rad tokom i nakon završetka studija. Pojedini autori izražavaju sumnju u razvoj obrazovnog sistema u smislu implementiranja praktičnog rada i sticanja neophodnih veština koje treba da odgovore na konstantan i dinamičan razvoj turizma i hotelijerstva [3].

$\mathrm{Na}$ Departmanu za geografiju, turizam i hotelijerstvo, Prirodno-matematičkog fakulteta u Novom Sadu, prepoznata je neophodnost sticanja praktičnih znanja tokom studija u cilju osposobljavanja studenata za budući rad. Stoga se insistira na praktičnoj nastavi u turističkougostiteljskim objektima, kao i na savladavanju rada u softverima za vođenje istih (npr. Micros-Fidelio Suite 8).

\section{Hotelske informacione tehnologije (HIS)}

Nagli razvoj tehnologije i primena u hotelijerstvu doprineo je promeni tradicionalnog hotelskog poslovanja, odnosno automatizaciji brojnih procesa koji su olakšali svakodnevne aktivnosti hotelijera s jedne strane, i unapredili kvalitet usluge, $s$ druge strane.

Svakako, primena ovih tehnologija varira u zavisnosti od veličine i tipa ugostiteljskog objekta. U vezi sa tim, kategorija hotela i dodatne usluge koje se u njemu pružaju, takođe će uticati na obim primene informacionih tehnologija. Ne treba smetnuti s uma da profil gostiju takođe ima važan uticaj na odabir i primenu informacionih tehnologija, posebno u hotelima sa izgrađenim brendom.

Primena informacionih tehnologija se u velikoj meri primenjuje u cilju zadovoljenja potreba gostiju. U vezi sa tim, informacione tehnologije koriste se pri prijavi i odjavi gostiju, za VoD (video on demand), internet i druge poslovne aktivnosti putem interaktivnog TV prijemnika i sl. [4].

Ovakva tehnološka rešenja uticala su na znatna poboljšanja u radu, posebno u okviru hotelskih lanaca:

- poboljšanje operativne efikasnosti;

- olakšanje kontrole poslovanja;

- prikupljanje, arhiviranje i upotreba potrebnih informacija;

- sačinjavanje i realizovanje marketinških, prodajnih i operativnih izveštaja;

- poboljšanje marketing istraživanja i planiranja poslovnih operacija;

- evidentiranje i praćenje hotelskih gostiju;

- direktan marketing i posebne usluge za redovne goste;

- poboljšanje u domenu rezervacija, prodaje i naplate [5].
Property Management Systems (PMS)

Sistemi za upravljanje poslovnim operacijama (Property Management Systems) mogu se koristiti u oblasti nekretnina, logistike, proizvodnje, intelektualne svojine i u hotelijerstvu. To su kompjuterizovani sistemi koji softverom olakšavaju sve vrste upravljanja u pomenutim oblastima. Pojavili su se kao zamena zastarelih, papirnih metoda koje su naginjale da postanu glomazne i neefikasne [6].

U hotelijerstvu, PMS (npr. Micros-Fidelio Suite 8) je softver koji se koristi za automatizaciju poslovanja hotela. Nekada se veliki broj recepcionerskih radnji obavljao ručno. Danas je najveći broj tih radnji pojednostavljen zahvaljujući PMS-u. Ovakav sistem bazira se na informisanju gostiju, upravljanju poslovnim aktivnostima i umrežavanju svih poslovnih aktivnosti i funkcija u hotelu (recepcija, domaćinstvo, sektor hrane i pića, marketing i dr.) [7]. PMS doprinosi efikasnijem radu recepcije tako što isključuje mogućnost da se neka od recepcionerskih radnji ponovi i omogućava brz i tačan pristup informacijama. Poboljšava efikasnost rada, olakšava kontrolisanje baza podataka, smanjuje broj zaposlenog ljudstva i vreme koje je potrebno da se odgovori na zahteve klijenata i zaposlenih.

U novije vreme raspoloživi su mnogobrojni PMS, a hotelske kompanije se prvenstveno opredeljuju za neki na osnovu veličine i tipa objekta, potreba hotela povezanih sa profilom gostiju, odnosno na osnovu tržišne opredeljenosti, tehničkih mogućnosti koje pruža PMS i njegove kompatibilnosti sa drugim IT, dostupnosti na tržištu i cenovnog ranga ovakvog softverskog rešenja. Trenutno su na tržištu najzastupljenije PMS kompanije Oracle, Opera i Micros-Fidelio Suite, koji je nedavno promenio naziv u Oracle Hospitality Suite. U Tabeli 1 prikazani su najzastupljeniji sistemi koji se mogu naći na tržištu.

\section{Micros-Fidelio}

Micros-Fidelio je nastao partnerstvom dve kompanije: Micros System iz SAD, i Fidelio iz Nemačke.

Micros je lider u razvoju informacionih sistema za restoransko poslovanje, koji uključuju i hardver i softver za POS i operativne aplikacije, a razvija i back office sisteme koje uključuju upravljanje zalihama, finansijama i kadrovima.

Fidelio omogućava hotelima i lancima hotela (bilo koje veličine i tipa), restoranima, organizatorima krstarenja i konferencija, ketering kompanijama da digitalizuju sve 
svoje operacije i integrišu glavne industrijske softverske proizvode kroz analizu individualnih zahteva.

Micros-Fidelio sistemi su najfunkcionalniji sistemi tog tipa na današnjem tržištu. Sa preko 50000 instalacija širom sveta, Micros-Fidelio sistemi mogu se naći u hotelima od 4 do 1000 soba.

Fidelio Verzija 8 je kompletno integrisan, fleksibilan softverski paket, dizajniran da maksimalno poveća efikasnost hotelskog poslovanja. Sistem sadrži sve funkcije za dnevno poslovanje hotela, uključujući i sve aspekte hotelskog menadžmenta i održavanja. Podržava sve zahteve hotelijerstva, od osnovne usluge, do kompleksnih i luksuznih usluga. Fidelio Verzija 8 baziran je na Oracle ${ }^{\odot}$ tehnologiji, integrisan, veb orijentisan. To je prilagodljiv softverski paket, parametarski orijentisan [9].

\begin{tabular}{|c|c|c|}
\hline PMS & $\begin{array}{c}\text { Broj } \\
\text { komitenata }\end{array}$ & $\begin{array}{c}\text { Broj } \\
\text { korisnika }\end{array}$ \\
\hline Oracle & 26000 & 104000 \\
\hline eZee Technosys & 6000 & 91000 \\
\hline InnQuest & 5500 & 70000 \\
\hline Hotelogix & 1150 & 22000 \\
\hline MSI & 5800 & 21000 \\
\hline Frontdesk Anywhere & 1400 & 18000 \\
\hline Guestline & 3000 & 10000 \\
\hline RDP & 1000 & 22000 \\
\hline GuestTracker & 2500 & 10500 \\
\hline Open Hotel & 78 & 35000 \\
\hline BookingCenter & 1835 & 7800 \\
\hline Hotello & 350 & 12250 \\
\hline base7booking & 613 & 7315 \\
\hline Maestro & 430 & 10000 \\
\hline WebRezPro & 900 & 4500 \\
\hline RoomKeyPMS & 800 & 7200 \\
\hline IQware & 325 & 10245 \\
\hline ibelsa & 830 & 3320 \\
\hline Easy Innkeeping & 600 & 9000 \\
\hline Clerk & 246 & 836 \\
\hline
\end{tabular}

Tabela 1. Prikaz najzastupljenijih PMS u hotelijerstvu. Izvor: [8].

\section{METODOLOGIJA}

Istraživanje je sprovedeno u martu 2017. godine na Departmanu za geografiju, turizam i hotelijerstvo, a u njemu su učestvovali studenti hotelijerstva i turizma $(n=100)$, koji u okviru predmeta Hotelska prodaja i recepcijsko poslovanje prolaze obuku za rad u softveru za upravljanje hotelom Micros-Fidelio Suite 8. Istraživanje je sprovedeno onlajn pomoću upitnika koji su kreirali autori rada.

\section{REZULTATI RADA}

Od ukupnog broja ispitanika, 77\% čine žene, a većina ispitanika je sa smera hotelijerstvo (69\%), dok je 31\% ispitanika sa smera turizam.

Na pitanje: Da li ste imali priliku da koristite drugi softverski paket osim Fidelia Suite 8 ? svega 16\% ispitanika odgovorilo je sa da, a programi koje su koristili su 2DHotelijer, EHotel, Hotel Soft, Hotelijer, Opera. Takođe, svega $23 \%$ ispitanika bilo je upoznato sa softverskim paketom Fidelio Suite 8 pre obuke na fakultetu.

U Tabeli 2 prikazane su srednje vrednosti odgovora na tvrdnje u vezi sa značajem obuke iz Micros-Fidelio Suite 8 tokom studija. Iz Tabele se vidi da su studenti uglavnom pozitivno ocenjivali tvrdnje u vezi sa korišćenjem ovog softvera kao sastavnog dela nastavnog plana i programa (srednje vrednosti su uglavnom preko 4). Nešto nižu srednju vrednost odgovora možemo uočiti kod pitanja: Pojedini simboli koji postoje me zbunjuju, nisu dobro predstavljeni i Sve opcije ovog sistema su lake za savladavanje, što govori o tome da pojedinim studentima nije toliko lako da savladaju program, iako smatraju da je to za njih značajno. Takođe, veoma mala srednja vrednost $(\mathrm{M}=2)$ odgovora na tvrdnju: Smatram da je obuka za korišćenje ovakvih softvera nepotrebna na fakultetu govori o tome da student uviđaju korisnost i značaj ove obuke. Rezultati su prikazani u Tabeli 2.

U sledećem koraku sproveden je t-test nezavisnih uzoraka sa ciljem da se utvrdi da li postoju statistički značajna razlika između muškaraca i žena po pitanju tvrdnji vezanih za korišćenje i značaj programa Micros-Fidelio Suite 8. Test je pokazao značajnu razliku samo u slučaju dve tvrdnje: Smatram da je obuka za korišćenje ovakvih softvera nepotrebna na fakultetu i Pojedini simboli koji postoje me zbunjuju, nisu dobro predstavljeni. Muškarci su ostvarili više skorove u odnosu na oba pitanja, što znači da muškarci, za razliku od žena, više smatraju da je obuka za korišćenje ovakvih softvera nepotrebna fakultetu, kao i da pojedini simboli nisu dobro predstavljeni. Rezultati su prikazani u Tabeli 3. 


\begin{tabular}{lcc}
\hline \multicolumn{1}{c}{ Tvrdnje } & M & $\begin{array}{c}\text { Stand- } \\
\text { ardna } \\
\text { devijacija }\end{array}$ \\
\hline $\begin{array}{l}\text { Obuka za korišćenje softvera omogućava } \\
\text { studentima bolje pozicioniranje i lakše } \\
\text { zaposlenje u struci. }\end{array}$ & 4,18 & 1,073 \\
\hline $\begin{array}{l}\text { Obuka za korišćenje softvera omogućava } \\
\text { studentima sticanje samopouzdanja za } \\
\text { budući rad u struci. }\end{array}$ & 4,18 & 0,970 \\
\hline
\end{tabular}

Odluka Fakulteta da u nastavni plan i program, u okviru predmeta Hotelska prodaja i recepcijsko poslovanje, uključi obaveznu obuku za korišćenje softvera Fidelio Suite 8, u skladu je sa najnovijim trendovima u obrazovanju iz oblasti hotelijerstva.

\begin{tabular}{|c|c|c|}
\hline $\begin{array}{l}\text { Softverski paket je jednostavan za } \\
\text { korišćenje. }\end{array}$ & 4,03 & 1,013 \\
\hline $\begin{array}{l}\text { Softverski paket predstavlja inovaciju i } \\
\text { proizvod moderne tehnologije. }\end{array}$ & 4,13 & 1,080 \\
\hline $\begin{array}{l}\text { Sve opcije ovog sistema su } \\
\text { lake za savladavanje. }\end{array}$ & 3,97 & 1,063 \\
\hline Ovaj sistem je brz i efikasan. & 4,23 & 0,986 \\
\hline $\begin{array}{l}\text { Pronalaženje podataka je lako u } \\
\text { aplikacijama koje se koriste. }\end{array}$ & 4,13 & 1,056 \\
\hline $\begin{array}{l}\text { Aplikacije koje se koriste usklađene su } \\
\text { sa zadacima koji treba da se obavljaju u } \\
\text { svakodnevnom poslovanju. }\end{array}$ & 4,36 & 0,903 \\
\hline $\begin{array}{l}\text { Softver može da podrži sve što radni } \\
\text { proces zahteva. }\end{array}$ & 4,36 & 0,959 \\
\hline $\begin{array}{l}\text { Dobijanje informacija iz ovog sistema na } \\
\text { vreme unapređuje rad zaposlenih u } \\
\text { hotelu. }\end{array}$ & 4,38 & 0,935 \\
\hline $\begin{array}{l}\text { Ovaj sistem je dizajniran za sve } \\
\text { nivoe korisnika. }\end{array}$ & 4,13 & 1,005 \\
\hline $\begin{array}{l}\text { Omogućeno je kreiranje raznovrsnih } \\
\text { izveštaja i statistika. }\end{array}$ & 4,44 & 0,940 \\
\hline $\begin{array}{l}\text { Dodeljivanje VIP statusa klijentima i } \\
\text { pronalaženje istih u sistemu je } \\
\text { jednostavno i brzo. }\end{array}$ & 4,46 & 0,854 \\
\hline Fleksibilan je prilikom naplate zaduženja. & 4,44 & 0,968 \\
\hline $\begin{array}{l}\text { Omogućava uvid u strukturu svih } \\
\text { podataka u svakom trenutku. }\end{array}$ & 4,49 & 0,854 \\
\hline $\begin{array}{l}\text { Ikonice koje su korišćene olakšavaju } \\
\text { snalaženje korisnicima. }\end{array}$ & 4,31 & 1,030 \\
\hline Obuka je dobro organizovana. & 4,13 & 1,239 \\
\hline $\begin{array}{l}\text { Zadovoljan sam prikazom simbola } \\
\text { koji postoje. }\end{array}$ & 4,15 & 0,933 \\
\hline $\begin{array}{l}\text { Pojedini simboli koji postoje me } \\
\text { zbunjuju, nisu dobro predstavljeni. }\end{array}$ & 2,90 & 1,392 \\
\hline
\end{tabular}

Korišćenje ovog softverskog sistema u hotelijerstvu doprinosi uštedi vremena.

Korišćenje ovog softverskog sistema u hotelijerstvu doprinosi uštedi materijalnih $\quad 4,44$ 0,912 sredstava.

\begin{tabular}{lcc}
\hline $\begin{array}{l}\text { Zadovoljan sam primenom } \\
\text { softverskog sistema. }\end{array}$ & 4,38 & 0,963 \\
\hline $\begin{array}{l}\text { Imao/Imala sam averziju prema } \\
\text { obuci za korišćenje softvera. }\end{array}$ & 2,69 & 1,490 \\
\hline $\begin{array}{l}\text { Smatram da je obuka za korišćenje } \\
\text { ovakvih softvera nepotrebna na fakultetu. }\end{array}$ & 2,00 & 1,539
\end{tabular}

Tabela 2. Srednje vrednosti odgovora na tvrdnje u vezi sa značajem i upotrebom programa Fidelio Suite 8.

\begin{tabular}{lccc} 
& $\mathbf{t}$ & Sig. & $\begin{array}{c}\text { Mean } \\
\text { Differ- } \\
\text { ence }\end{array}$ \\
\hline $\begin{array}{l}\text { Smatram da je obuka } \\
\begin{array}{l}\text { za korišćenje ovakvih } \\
\text { softvera nepotrebna na } \\
\text { fakultetu. }\end{array}\end{array}$ & 3,364 & 0,002 & 1,578 \\
\hline $\begin{array}{l}\text { Pojedini simboli } \\
\text { koji postoje me } \\
\text { zbunjuju, nisu } \\
\text { dobro predstavljeni. }\end{array}$ & 3,711 & 0,001 & 1,878 \\
\hline
\end{tabular}

Tabela 3. Rezultati t-testa nezavisnih uzoraka.

Istraživanje je, takođe, pokazalo da su studenti hotelijerstva ostvarili statistički značajno veće ocene na testu $(p<0,05)$ od studenata turizma, kao i da su žene uspešnije od muškaraca $(\mathrm{p}<0,01)$, odnosno da na testu ostvaruju veći broj bodova.

\section{ZAKLJUČAK}

Savremene informacione tehnologije dovode do promena u načinu poslovanja u hotelijerstvu. Tehnološki razvoj, naročito na području informacione tehnologije, već je u znatnoj meri transformisao hotelsko poslovanje i odnos zaposlenih prema gostima. Dosadašnja iskustva pokazuju da je u hotelijerstvu sposobnost prilagođavanja hotelskog menadžmenta i uslužnog osoblja u celini, odlučujući faktor u pozitivnom reagovanju na uvođenje informacione tehnologije. Ovo prilagođavanje moguće je postići sveobuhvatnim obrazovanjem koje se mora periodično ponavljati, shodno razvoju informacione tehnologije. $U$ vezi sa tim, obrazovne institucije moraju staviti veći akcenat na praktičnu primenu znanja, odnosno na osposobljavanje studenata u skladu sa aktuelnim zahtevima tržišta rada (poslodavaca). Korist od ovakvog pristupa obrazovanju je višestruka i multiplikujuća. Fakulteti postaju 
konkurentniji i prepoznatljiviji, studenti spremniji za rad, a poslodavci dobijaju kvalifikovan kadar, u ovom slučaju iz oblasti hotelijerstva, koji je inače deficitaran.

\section{LITERATURA}

[1] N. Ralević, V. Đaković, M. Sujić, J. Kiurski, Lj. Nedović. "Mesto, uloga i značaj obrazovanja i učenja tokom života: strategija održivog razvoja integrativnog okruženja”, Zbornik radova. XVIII Skup - Trendovi Razvoja: "Internacionalizacija univerziteta”, 2012, pp. 1-4.

[2] J. Wang, H. Ayres, J. Huyton. "Job ready graduates: A tourism industry perspective". Journal of Hospitality \& Tourism Management, vol. 16, pp. 62-72, 2009.

[3] H.J. Yang, C. Cheung, C. Fang. "An empirical study of hospitality employability skills: perceptions of entry-level hotel staff in China". Journal of Hospitality \& Tourism Education, vol. 27, pp. 161-170, 2015.
[4] Lj. Kosar. Hotelijerstvo I. Beograd: Visoka hotelijerska škola, 2008.

[5] Lj. Kosar, N. Svorcan. Poslovanje recepcije i hotelskog domaćinstva. Beograd: Visoka hotelijerska škola strukovnih studija, 2008.

[6] V. Spasić, D. Pavlović. "Efekti primene savrmene informacione tehnologije $\mathrm{u}$ poslovanju malih turističkih agencija". Časopis za teoriju i praksu finansija, bankarstva, revizije i osiguranja, vol. 5, pp. 148-156, 2008.

[7] D. Barjaktarović. Upravljanje kvalitetom u hotelijerstvu. Beograd: Univerzitet Singidunum, 2013, pp. 240-45.

[8] J. Champagne. "The top 20 most popular hospitality property management software". Internet: http:// www.capterra.com/hospitality-property-management-software/\#infographic. [Oct. 15, 2016].

[9] "Fidelio Suite 8" Internet: http://www.micros.rs/ index.php, [Oct. 18, 2016]. 